$16^{\text {th }}$ International Conference on

AEROSPACE SCIENCES \& AVIATION TECHNOLOGY,

ASAT - 16 - May 26 - 28, 2015, E-Mail: asat@ mtc.edu.eg

Military Technical College, Kobry Elkobbah, Cairo, Egypt

Tel : +(202) 24025292 - 24036138, Fax: +(202) 22621908

\title{
PRELIMINARY DESIGN OF A HYDROGEN PEROXIDE THRUSTER FOR REMOTE SENSING SATELLITE
}

\author{
Ah. Deif ${ }^{*}$, A. El-Zahaby ${ }^{\dagger}$, Ah. El-S. Makled*, M. Khalil ${ }^{*}$
}

\begin{abstract}
In recent years, mono-propellant propulsion has attracted widespread attention in space due to excessive benefits of safety, low cost, simplicity, clean exhaust and high reliability. A 5N monopropellant Hydrogen Peroxide $\left(\mathrm{H}_{2} \mathrm{O}_{2}\right)$ thruster is selected to be utilized with remote sensing (RS) satellites for attitude control and orbit correction.

In the present paper, comprehensive theoretical analysis and design parameters are investigated. The effects of change in various design parameters are studied, such as operating pressures (7-16 bar), $\mathrm{H}_{2} \mathrm{O}_{2}$ concentration (70-95\%) and initial temperature $\left(25-70^{\circ} \mathrm{C}\right)$. The crucial design performance of thruster has been carried out by using thermo-chemical software package. A conceptual design was conducted to determine the dimensions of the thruster prototype including the injector plate, catalytic bed, retainer and nozzle part. $70^{\circ} \mathrm{C}$ $\mathrm{H}_{2} \mathrm{O}_{2}$ preheating temperature might be needed for catalytic bed fast response. The results are described in the form of graphs and tables for the quick and easy analysis.
\end{abstract}

Keywords: Monopropellant, thrusters, space propulsion system, catalytic bed, hydrogen peroxide

\section{INTRODUCTION}

Generally, the purpose of satellite propulsion system is to provide the total impulse required for damping of the random angular velocities of the satellite after separation from launcher, launch window error correction, orbit manoeuvres, orbit correction and finally the disposal after the end of lifetime of the satellite.

Particularly, the monopropellant thrusters (MPT) are a widespread used type due to its excessive benefits of low cost, simplicity, high reliability and safety. As their name indicates, MPT relies on a single propellant instead of two as bi-propellant propulsion system. The release of energy within the chemical bonds of the mono-propellant is promoted by a catalyst bed with special material and specification as shown in Fig.(1).

The concept of MPT has been utilized in my applications for propulsion and power in the past 60 years. It is important to understand the essential trade-offs for MPT via the evaluation of mono-propellant system and its design parameters.

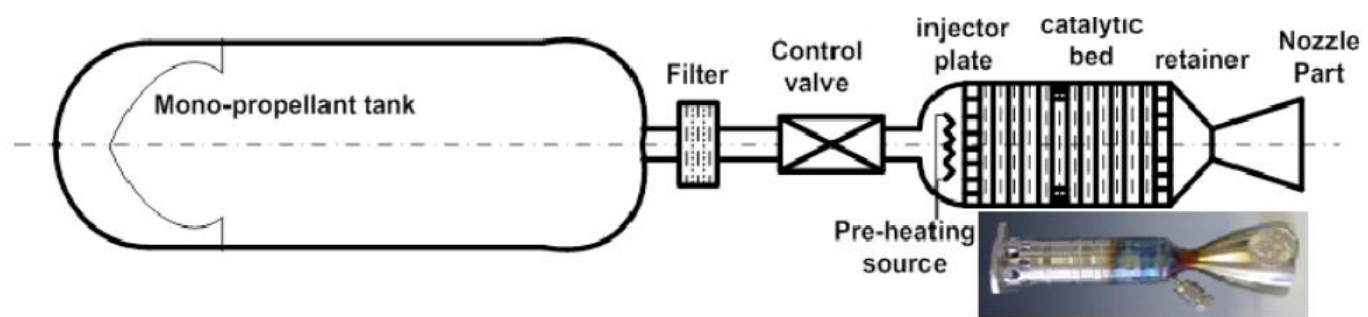

Fig. (1) General scheme mono-propellant propulsion system

\footnotetext{
* Egyptian Armed Forces, Egypt.

$\dagger$ Tanta University, Egypt.
} 


\section{EVALUATION OF MONO-PROPELLANT SYSTEM FOR SPACE}

Mono-propellant system offers a number of advantages over the traditional chemical propulsion systems (liquid, solid and hybrid), particularly in the areas of re-start and throttling operations, safety, cost and environmental effects.

\section{2-1: System Benefits}

- Flight heritage in space,

- No combustion tends to clean exhaust, safe, and low risk of hypergolic reaction,

- Single propellant tends to simpler plumbing and construction,

- Simpler flow trimming tends to controllability and re-start,

- Smaller amount performance variables (Shorter impulse bit thruster),

- Better center gravity control shaft,

- Two modes of operation, steady state and pulse to pulse modes,

- Multi task purpose (ignition, propulsion, gas generator).

\section{2-2: System Drawbacks}

- Lower specific impulse (25\% less),

- Lower density specific impulse (35\% less),

- Limited space missions specially for orbit transfer (limited delta velocity budget),

- Pre-heating is sometimes needed to promote catalyst pack,

- Lower thruster efficiency $(\approx 85-90 \%)[2,3]$,

- Catalyst bed efficiency degradation.

\section{SELECTION CRITERIA OF PROPELLANT}

The total potential lists of mono-propellants may include:

Nitrous oxide $\mathrm{N}_{2} \mathrm{O}$, Hydrogen peroxide $\mathrm{H}_{2} \mathrm{O}_{2}$, Hydrazine $\mathrm{N}_{2} \mathrm{H}_{4}$, Nitromethane $\mathrm{C}_{1} \mathrm{H}_{3} \mathrm{~N}_{1} \mathrm{O}_{2}$, Nitroglycerine $\mathrm{C}_{3} \mathrm{H}_{5} \mathrm{~N}_{3} \mathrm{O}_{9}$, Ethyl nitrate $\mathrm{C}_{2} \mathrm{H}_{5} \mathrm{NO}_{3}$, Tetronitromethane $\mathrm{CN}_{4} \mathrm{O}_{8}$, Ethylene oxide $\mathrm{C}_{2} \mathrm{H}_{4} \mathrm{O}$, Isopropyl nitrate $\mathrm{C}_{3} \mathrm{H}_{7} \mathrm{~N}_{7} \mathrm{O}_{3} \mathrm{~N}_{1}$, Hydroxyl Ammonium Nitrate $\mathrm{H}_{4} \mathrm{~N}_{2} \mathrm{O}_{4}$ [3].

Mono-propellant selection criteria (for satellite in low earth orbit (LEO) missions) should have the following characteristics:

1. Acceptability by launch agency,

2. High storage density as possible,

3. Space storability for 3-5 years at least,

4. Handling and safety during ground operations,

5. Availability in local market,

6. Ease of decomposition (exothermic reaction),

7. Cleanliness of exhaust products for satellite and environment.

Nowadays, the concerns of environmental preservation are raised all over the world and moreover, system conceptual design is driven by cost, time, and safety. Hydrazine $\mathrm{N}_{2} \mathrm{H}_{4}$ has high toxicity and carcinogenic nature requires high cost which makes propellant undesirable. $\mathrm{H}_{2} \mathrm{O}_{2}$ has been gaining a renewed interest to be used as an oxidizer in bi and hybrid propulsion systems, as well as, a monopropellant fuel. Moreover, utilization of $\mathrm{H}_{2} \mathrm{O}_{2}$ in propulsion provides the capability of operating the propulsion system on dual modes a bipropellant for a large thrust applications and a monopropellant mode for a small thrust requirement.

The decomposition process of $\mathrm{H}_{2} \mathrm{O}_{2}$ is assumed to be stoichiometric, the propellant flows through the catalyst bed and prompt decomposition to take place in an exothermic reaction according to the following governing equation:

$$
\mathrm{H}_{2} \mathrm{O}_{2} \stackrel{\text { Decomposition }}{\longrightarrow} \mathrm{H}_{2} \mathrm{O}_{\text {vapor }}+1 / 2 \mathrm{O}_{2 \text { Gas }}+\text { heat }
$$

The thermal energy (decomposition products) transferred to kinetic energy by expansion through a nozzle part; producing specific impulse $\mathrm{I}_{\mathrm{sp}} \approx 150 \mathrm{~s}$. Table (1) shows the important characteristics of $\mathrm{H}_{2} \mathrm{O}_{2}$. 
Table (1) The important characteristics of $\mathrm{H}_{2} \mathrm{O}_{2}$ [4]

\begin{tabular}{|l|c|}
\hline \multicolumn{1}{|c|}{ Parameter } & Value \\
\hline Density, $\mathrm{kg} / \mathrm{m}^{3}$ & 1388.00 \\
\hline Freezing point, ${ }^{\circ} \mathrm{C}$ & -17.90 \\
\hline Boiling point at $1 \mathrm{bar},{ }^{\circ} \mathrm{C}$ & 136.60 \\
\hline Specific heat at $20-60^{\circ} \mathrm{C}, \mathrm{kJ} / \mathrm{kg}-\mathrm{K}$ & 2.83 \\
\hline Latent heat of fusion, $\mathrm{kJ} / \mathrm{kg}$ & 367.60 \\
\hline Viscosity at $20^{\circ} \mathrm{C}, \mathrm{N}-\mathrm{s} / \mathrm{m}^{2}$ & $1.26 \times 10^{-3}$ \\
\hline
\end{tabular}

\section{MONO-PROPELLANT THRUSTER PERFORMANCE ESTIMATION}

The definition of the main design parameters and performance of the thruster were based on the following sources:

1) Theoretical results based on thermo-chemical calculation software [4],

2) Data based on previous experimental work [3, 5,6,7],

3) Calculations of design and analysis parameters.

\section{4-1: Theoretical Results}

Theoretical results of MPT performance could be obtained using standard thermo-chemical calculation software or by theoretical calculations. The thruster parameters were evaluated using NASA's CEA code [4], the output data is shown in Table (2). Various design parameters for all data outputs based on the earlier assumptions for the concentrations range of $70-95 \%$ of $\mathrm{H}_{2} \mathrm{O}_{2}$ were shown in Fig (2,3, and 4). Decomposition takes place at an assumed frozen flow inside the chamber, operating pressure from 7-16 bar, exit pressure equal to 1 bar and two initial $\mathrm{H}_{2} \mathrm{O}_{2}$ temperature values 25 and $70^{\circ} \mathrm{C}$.

The thermo- chemical analysis for $\mathrm{H}_{2} \mathrm{O}_{2}$ decomposition products as shown in Table (3).

Table (2) Thermo-chemical calculations, NASA's CEA print out sheet [4]

THEORETICAL ROCKET PERFORMANCE ASSUMING FROZEN COMPOSITION

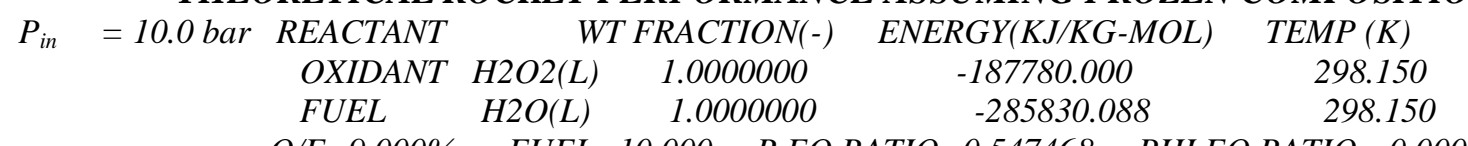

\begin{tabular}{|c|c|c|c|}
\hline Property & CHAMBER & THROAT & $\frac{I U=0.000}{E X I T}$ \\
\hline Pressure ratio,(-) & 1.0000 & 1.8187 & 10.000 \\
\hline Operating pressure $P c,($ bar $)$ & 10.000 & 5.4984 & 1.0000 \\
\hline Chamber temp.Tc, $(K)$ & 1029.59 & 906.51 & 616.43 \\
\hline Density, $(\mathrm{kg} / \mathrm{m} 3)$ & 2.5821 & 1.6125 & $4.3128-1$ \\
\hline Enthalpy $H,(K J / K g)$ & -6555.10 & -6772.68 & -7256.24 \\
\hline Molecular weight $M, \mathrm{~kg} / \mathrm{kmol}$ & 22.105 & 22.105 & 22.105 \\
\hline $\begin{array}{l}\text { Specific heat at constant pressure } \\
C_{p}, K J /(K G-K)\end{array}$ & 1.7972 & 1.7381 & 1.5954 \\
\hline Specific heat ration (-) & 1.2647 & 1.2762 & 1.3085 \\
\hline
\end{tabular}

PERFORMANCE PARAMETERS

\begin{tabular}{|l|c|c|}
\hline \multicolumn{1}{|c|}{ Ae/At } & $\mathbf{1 . 0 0 0 0}$ & $\mathbf{2 . 0 8 2 8}$ \\
\hline${\text { Characteristic velocity } C^{*}{ }_{t h},(\mathrm{~m} / \mathrm{s})}^{\text {Phrust coefficient } C_{f,}(-)}$ & 940.1 & 940.1 \\
\hline Vacuum specific impulse I $_{\text {spv }},(\mathrm{m} / \mathrm{s})$ & 0.7017 & 1.2596 \\
\hline specific impulse Isp, $(\mathrm{m} / \mathrm{s})$ & 1176.6 & 1380.0 \\
\hline
\end{tabular}

MOLE FRACTIONS

$\begin{array}{llll}H 2 O & 0.70757 & O 2 & 0.29243\end{array}$


Table (3) $\mathrm{H}_{2} \mathrm{O}_{2} 85 \%$ decomposition products

\begin{tabular}{|l|c|c|c|}
\hline \multicolumn{1}{|c|}{ Parameter } & $\mathrm{H}_{2} \mathrm{O}_{2}$ & $\mathrm{H}_{2} \mathrm{O}$ steam & $\mathrm{O}_{2}$ Gas \\
\hline Density at $25 \mathrm{C}, \mathrm{kg} / \mathrm{m}^{3}$ & 1374.0 & 1000.0 & 0.0 \\
\hline Heat of formation, $\mathrm{kJ} / \mathrm{mol}$ & -187.7 & -285.8 & 0.0 \\
\hline Molar mass, $\mathrm{kg} / \mathrm{kmol}$ & 34.0 & 18.0 & 32.0 \\
\hline
\end{tabular}

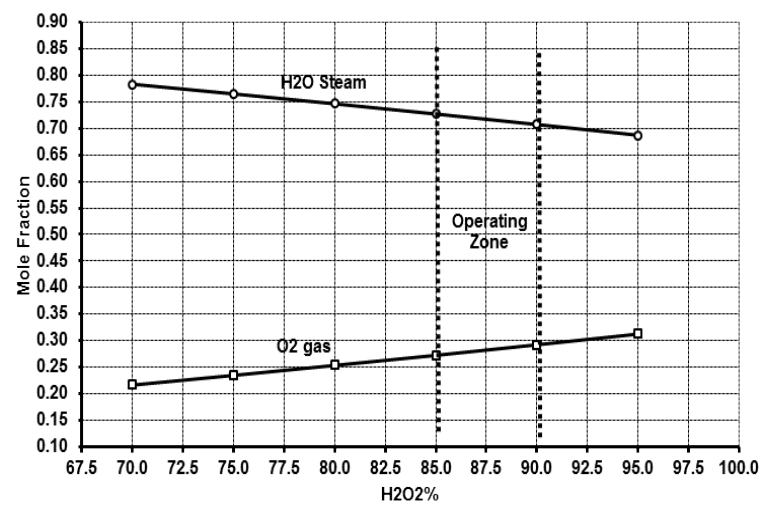

(a) Mole fraction $\left(\mathrm{H}_{2} \mathrm{O} \& \mathrm{O}_{2}\right)$ versus $\mathrm{H}_{2} \mathrm{O}_{2}$ Concentration

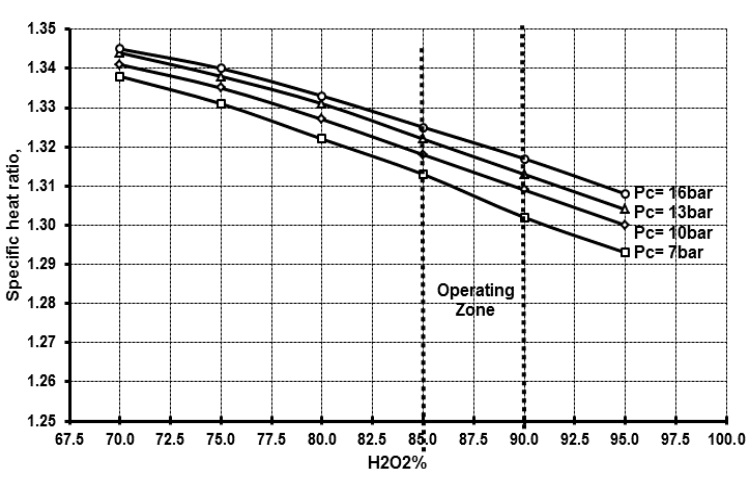

(c) Specific heat ratio versus $\mathrm{H}_{2} \mathrm{O}_{2}$ concentration

Fig. (2)Thermo-chemical parameters versus $\mathrm{H}_{2} \mathrm{O}_{2}$ concentration and operating pressures

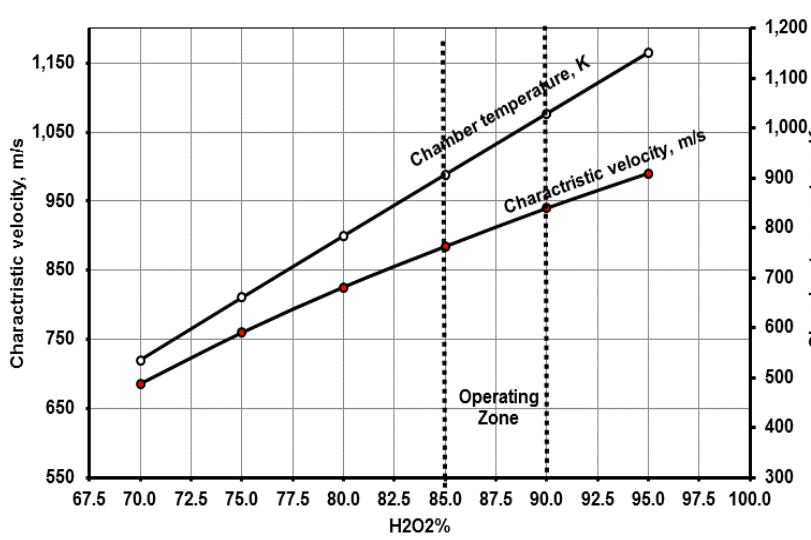

Fig. (3) Characteristic velocity and chamber temperature versus $\mathrm{H}_{2} \mathrm{O}_{2}$ concentration

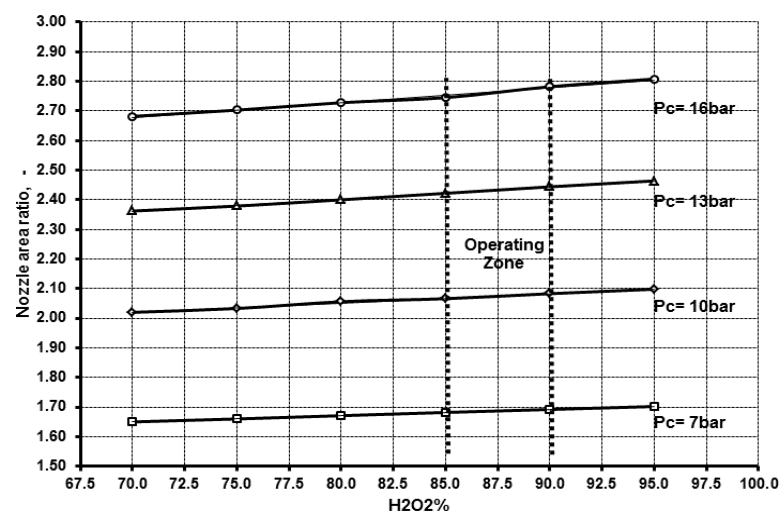

(b) Nozzle area ratio Versus $\mathrm{H}_{2} \mathrm{O}_{2}$ concentration

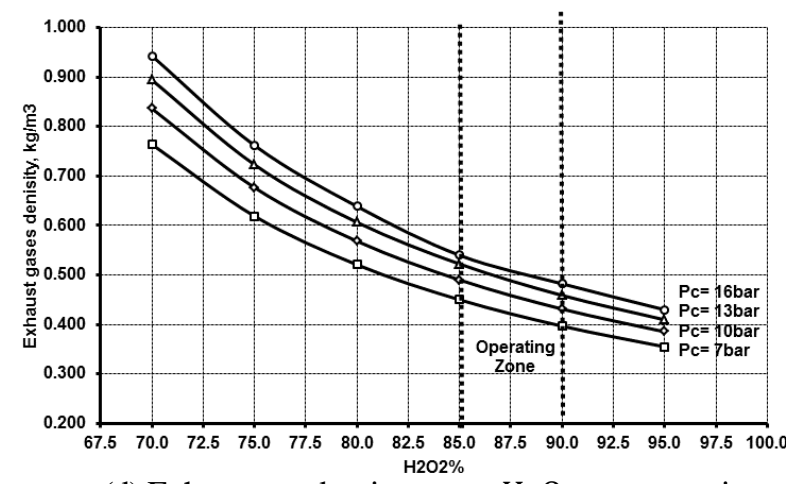

(d) Exhaust gas density versus $\mathrm{H}_{2} \mathrm{O}_{2}$ concentration

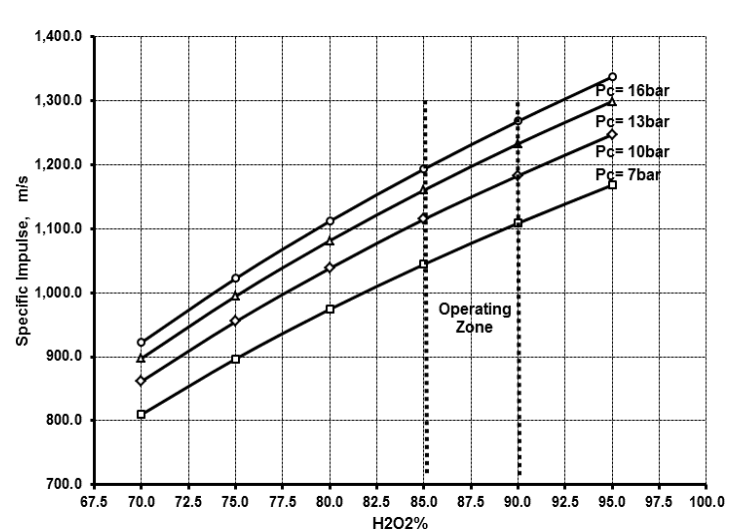

Fig. (4) Specific impulse Versus $\mathrm{H}_{2} \mathrm{O}_{2}$ concentration

\section{4-1-1: Discussion and Analysis}

\section{- Effect of Variation of $\mathrm{H}_{2} \mathrm{O}_{2}$ Concentration\%}

Figure (2-a) shows that as the concentration of $\mathrm{H}_{2} \mathrm{O}_{2}$ increases, the amount of the decomposed gaseous $\mathrm{O}_{2}$ increases proportionally. The amount of the decomposed $\mathrm{O}_{2}$ at $\mathrm{H}_{2} \mathrm{O}_{2} 95 \%$ concentration is $\approx 50 \%$ higher than $\mathrm{H}_{2} \mathrm{O}_{2} 70 \%$ concentration. Figure (2-b) shows that as $\mathrm{H}_{2} \mathrm{O}_{2} \%$ concentration increases, the nozzle area ratio increases slightly. Figures (2-c\&d) show that as the $\mathrm{H}_{2} \mathrm{O}_{2} \%$ concentration increases, the specific heat ratio $\gamma$ decreases inversely 
proportional at the same operating pressure $\mathrm{P}_{\mathrm{c}}$, as well as, the exhaust gases density $\rho$ decreases proportionally as the $\mathrm{H}_{2} \mathrm{O}_{2} \%$ concentration increases because the chamber temperature $T_{c}$ increases so consequently, $\rho$ decreases. Figures ( $\left.3 \& 4\right)$ show that as $\mathrm{H}_{2} \mathrm{O}_{2} \%$ concentration increases, characteristic velocity $\mathrm{C}^{*}$, specific impulseI $_{\mathrm{sp}}$, and chamber temperature $\mathrm{T}_{\mathrm{c}}$, increase proportionally at the same operating chamber pressure $\mathrm{P}_{\mathrm{c}}$. Consequently, it enhances the performance of the thruster but in the meanwhile, the increase of $\mathrm{T}_{\mathrm{c}}$ increases the chamber mass and puts more restriction on the selection of the thruster and catalyst bed material. The $\mathrm{I}_{\mathrm{sp}}$ rise puts more restriction on the choice of the catalyst bed service life. It is noticed that $\mathrm{T}_{\mathrm{c}}$ increases (15\%) within the selected operating $\mathrm{H}_{2} \mathrm{O}_{2}$ concentrations (85\%-90\%) but increasing $\mathrm{H}_{2} \mathrm{O}_{2}$ concentration from 70 to $95 \%$, increases $\mathrm{T}_{\mathrm{c}}$ about $(115 \%)$ of $\mathrm{T}_{\mathrm{c}}$ at $70 \%$.

- Effect of Variation of Operating Pressure

Figure (2) shows effects of variation of $P_{c}$ on MPT performance. It is noticed that changing $P_{c}$ doesn't influence mole fraction of $\mathrm{H}_{2} \mathrm{O}_{2}, \mathrm{O}_{2}$, and $\mathrm{C}^{*}$ but, slight variation of specific heat ratio $\gamma$ takes place.

\section{- Effect of Variation of $\mathrm{H}_{2} \mathrm{O}_{2}$ Initial Temperature}

Table (4) and Figure (5) Show that, increasing $\mathrm{H}_{2} \mathrm{O}_{2}$ initial temperature $T_{i}$, increases $I_{s p}$ and $C^{*}$ at the same $P_{c}$ for different $\mathrm{H}_{2} \mathrm{O}_{2}$ concentrations, so it enhances the performance of the thruster. It is also noticed that the contribution of increase of $I_{s p}$ and $C^{*}$ by increasing the $\mathrm{H}_{2} \mathrm{O}_{2} \mathrm{~T}_{i}$ decreases slightly by increasing the $\mathrm{H}_{2} \mathrm{O}_{2} \%$ concentration. The increase of $\mathrm{I}_{s p}$ at $\mathrm{H}_{2} \mathrm{O}_{2} 70 \%$ due to increase in $\mathrm{T}_{i}$ of $45^{\circ} \mathrm{C}$ is $68.7 \mathrm{~m} / \mathrm{s}$.In the meanwhile, the increase of $I_{s p}$ at $\mathrm{H}_{2} \mathrm{O}_{2} 95 \%$ due to the same increase in $T_{i}$ is $51.9 \mathrm{~m} / \mathrm{s}$. As for $C^{*}$, the increase of $C^{*}$ at $\mathrm{H}_{2} \mathrm{O}_{2} 70 \%$, due to increase in $\mathrm{T}_{i}$ of $45^{\circ} \mathrm{C}$ is $53.4 \mathrm{~m} / \mathrm{s}$.In the meanwhile, the increase of $\mathrm{C}^{*}$ at $\mathrm{H}_{2} \mathrm{O}_{2} 95 \%$ due to increase in $\mathrm{T}_{i}$ of $45^{\circ} \mathrm{C}$ is $29.5 \mathrm{~m} / \mathrm{s}$.

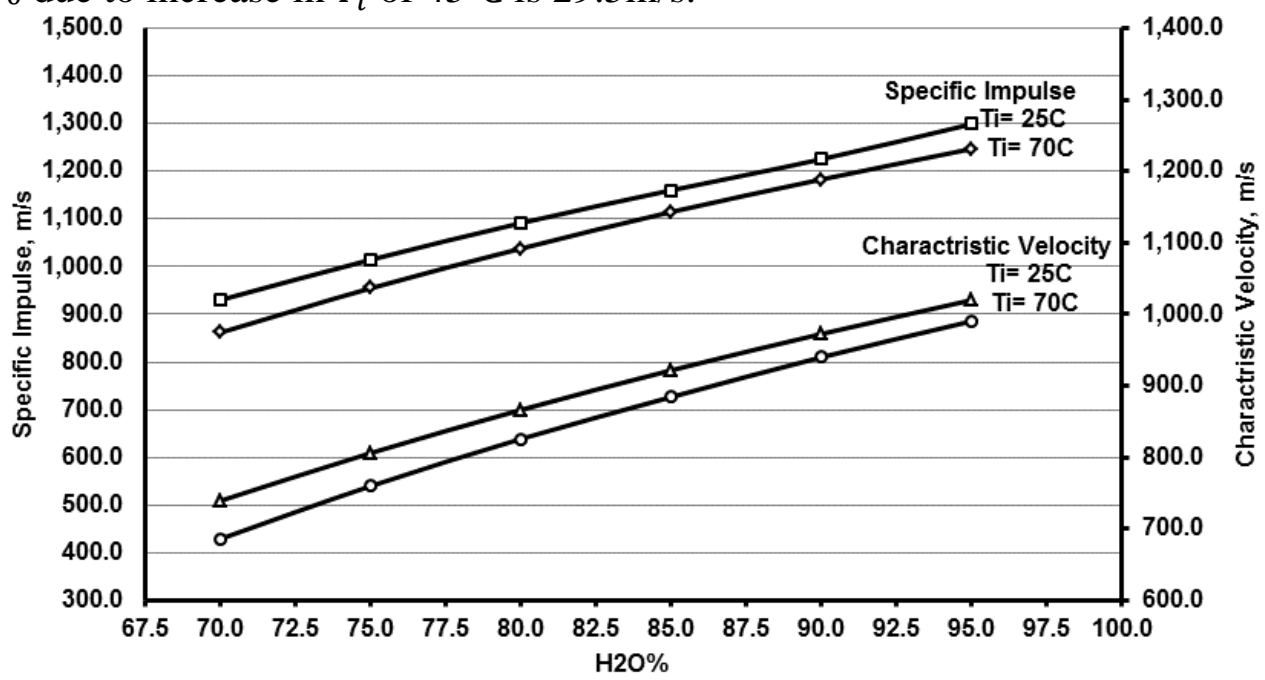

Fig. (5) Effect of $\mathrm{H}_{2} \mathrm{O}_{2}$ concentration and initial temperature on performance

Table (4) the effect of various temperature on thruster performance

\begin{tabular}{|c|c|c|c|c|c|c|c|c|c|}
\hline \multirow{2}{*}{$\begin{array}{l}\mathrm{H}_{2} \mathrm{O}_{2} \text { initial } \\
\text { temperature }\end{array}$} & \multirow{2}{*}{$\mathrm{H}_{2} \mathrm{O}_{2} \%$} & \multicolumn{2}{|c|}{ Mole fraction } & \multirow{2}{*}{$\mathbf{T}_{\mathbf{c}}, \mathbf{K}$} & \multirow{2}{*}{$\mathbf{I}_{\mathrm{sp}},(\mathrm{m} / \mathrm{s})$} & \multirow{2}{*}{$\mathbf{A}_{\text {ex }} / \mathbf{A}_{t}$} & \multirow[b]{2}{*}{$\gamma$} & \multirow{2}{*}{$\begin{array}{c}C^{*} \\
\mathbf{m} / \mathbf{s}\end{array}$} & \multirow{2}{*}{$\rho\left(\mathrm{kg} / \mathrm{m}^{3}\right)$} \\
\hline & & $\mathrm{H}_{2} \mathrm{O}$ steam & $\mathrm{O}_{2}$ & & & & & & \\
\hline \multirow{2}{*}{$25^{\circ} \mathrm{C}$} & 85 & 0.7273 & 0.2728 & 907.3 & 1114.9 & 2.066 & 1.318 & 884.5 & 0.4902 \\
\hline & 90 & 0.7076 & 0.2924 & 1029.6 & 1183.1 & 2.083 & 1.309 & 940.1 & 0.4313 \\
\hline \multirow{2}{*}{$70^{\circ} \mathrm{C}$} & 85 & 0.7273 & 0.2728 & 980.3 & 1160.5 & 2.422 & 1.322 & 884.5 & 0.5224 \\
\hline & 90 & 0.7076 & 0.2924 & 1099.6 & 1233.0 & 2.444 & 1.313 & 940.1 & 0.4590 \\
\hline
\end{tabular}




\section{4-2: Data Based On Previous Experimental Work}

This section focuses on pervious data used for MPT. These parameters can be summarized as $[3,5,6,7]$ :

- $\mathrm{H}_{2} \mathrm{O}_{2}$ concentration $\approx 85 \%$,

- Nozzle divergent angle $=15^{\circ}$,

- Nozzle exit pressure $=1$ bar (Adiabatic nozzle),

- Ratio of catalytic bed length to diameter $\approx 3-4$,

- Injection and retainer plates thickness $\approx 1-2 \mathrm{~mm}$,

- Decomposition efficiency $\approx 87 \%$,

\section{4-3: Thruster Parts Design}

The chamber thicknesses, nozzle throat area, length of catalyst bed and concentration of $\mathrm{H}_{2} \mathrm{O}_{2}$ are considered here as a sizing parameters, which are used to meet the mission specified thrust profile.

The design process starts by specifying the required total impulse $I_{t o t}$ and average required thrust $F_{a v}$. The output includes; decomposition chamber design including; injection plate, catalytic bed, retainer, nozzle, and performance parameters specially $I_{s p}, T_{c}, C^{*}$, $P_{c}$, propellant mass flow rate $\dot{m}$.

\section{4-3-1: The decomposition chamber design}

Regarding the decomposition chamber, the first part where the liquid hydrogen is introduced and injected. The second part is the catalyst part which where the $\mathrm{H}_{2} \mathrm{O}_{2}$ is decomposed by flowing through it. The third part is where the gaseous products are accelerated into the throat section. The decomposition of $\mathrm{H}_{2} \mathrm{O}_{2}$ occurs within the catalyst bed and no combustion occurs in the third part. Hence, the length of the chamber after the catalyst should be minimized to reduce the heat transfer and the starting transients [2]. The cross-section area of the chamber should coincide with the catalyst, and the length of the chamber which is totally dependent on the catalyst bed design. Optimizing the cross- sectional area of the chamber is very vital to minimize the heat losses through the walls of the thruster $2 \mathrm{~mm}$ chamber thickness, $14.6 \mathrm{~mm}$ inner, and length of $58.4 \mathrm{~mm}$ have been calculated to satisfy the above considerations.

\section{4-3-2: Injection and retainer plates}

The main task of the injection plate is to produce a uniform distribution of the $\mathrm{H}_{2} \mathrm{O}_{2}$ flow through the catalyst bed and prevent the channeling of the flow. The retainer is placed inbetween the catalyst bed and the nozzle part to withstand the mechanical loads applied on the catalyst bed. An open area ratio of about $50 \%$ has been chosen for the plates, considering 2 $\mathrm{mm}$ diameter holes, this leads to a 23 -holes plate. The plate has been chosen to be stainless less like the thruster body with thickness of $\approx 1.5-2 \mathrm{~mm}$. the pressure drop across the injection plate is very low so the retainer plate is designed of equal open area to the injection plate; it is usually the retainer has a greater open ratio than injection plate in larger size thrusters. The most commonly used with MPT is the showerhead with concentric layout arrangement as shown in Fig. (8).

\section{4-3-3: Catalytic bed}

The $\mathrm{H}_{2} \mathrm{O}_{2}$ is introduced in the thruster through a central tube and passes through the distribution plate to the main catalyst bed material, where decomposition takes place. This design must assure a complete decomposition of all the $\mathrm{H}_{2} \mathrm{O}_{2}$ and provides high thrust efficiency assumed $87 \%$. The packing pressure depends on the throughput (loading factor) needed. The catalyst bed selection criteria as:

1. An adequate pressure drop to delink the feeding system,

2. Uniform mass flow without channeling or quenching and uniform heat transfer,

3. Shorter decomposition length, 
4. The capability of the catalyst bed to withstand the thermal and mechanical load of the decomposition process,

5. Maintainability of catalyst performance throughout the life time of the thruster,

6. Reasonable cost with high reliability

Various catalysts materials are investigated for $\mathrm{H}_{2} \mathrm{O}_{2}$ decomposition as $[5,8]$ :

1. Silver screens,

2. Silver-electroplated stainless steel screens,

3. Smarium oxide coated silver screen,

4. Coated ceramic pellet,

5. Alumina-deposited platinum,

Conventionally, $\mathrm{H}_{2} \mathrm{O}_{2}$ thrusters use silver screen or nickel screen plating with silver as catalysts. So far, silver screen is still the preferred choice, shows better durability for long periods of service. For better reactive decomposition, samarium nitrate has been proposed to promote the activity of silver screen. Considering the durability, cost, availability and activity, pure silver mesh or stainless steel coating with silver is selected as the catalyst of the $\mathrm{H}_{2} \mathrm{O}_{2}$ MPT in design.

The working life of the catalyst bed is restricted by pressure drop. The pressure drop of a catalyst bed is a function of the mass flow rate and downstream $\mathrm{P}_{c}$. Obviously, it is desired to maximize the mass flow rate while minimizing pressure drop. Pressure drop is driven by internal catalyst bed geometry, speed of reaction, and downstream chamber pressure. High downstream chamber pressure with a low mass flow rate will result in a low-pressure drop, just as opposite conditions will result in a high-pressure drop. A catalyst bed with a very lowpressure drop often floods or has chug-like pressure oscillations.

The starting rate of silver screen catalyst depends upon, $\mathrm{H}_{2} \mathrm{O}_{2}$ pre-heated temperature, and catalyst configuration. A 20x20 mesh is recommended for pure silver mesh (increase the catalyst surface area which shorten the starting transient), depth of pack and 40x40 for silver plated nickel mesh (recommended to be short as possible) and pack compression (it is better have higher heat conductivity).

The catalyst bed design parameters are presented in Fig. (6) and Table (6).

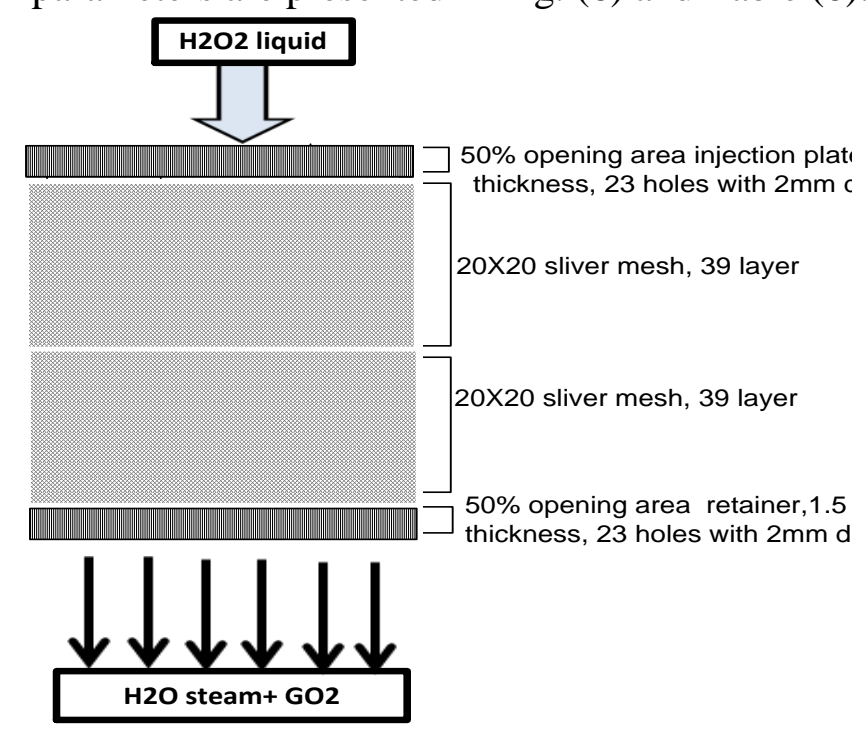

Fig. (6) Layout of catalyst bed design

\section{4-3-4: Nozzle part}

The nozzle part represented one of the most challenging aspects of the MPT design. It has to expand the exhaust gases from chamber $\mathrm{P}_{\mathrm{c}} \approx 10$ bar to ambient atmosphere $\mathrm{P}_{\mathrm{a}} \approx 1$ bar under the following conditions:

- Chamber temperature $\mathrm{T}_{\mathrm{c}} \approx 907.27^{\circ} \mathrm{C}$, 
- $\quad$ Expansion ratio $\approx 2.06$,

- High performance,

- Thermal cycling without fault,

The simple conical nozzle shape was selected to give an optimum expansion ratio.

\section{4-3-5: Thruster pressure losses}

The MPT presented by Fig. (8) consists of various parts include, injection (distribution) plate, catalytic bed, retainer and nozzle part. Each part has a certain pressure loss. Pressure drop through MPT should not be too low to link it with the feeding system and cause chugging instability or too high to increase the feeding system pressure.

- Injection and support plates loss

The pressure drop $\Delta \mathrm{P}$ across the injection plate depends on flow characteristics and orifice configuration can be calculated as.

$$
\Delta \mathrm{p}=\frac{\dot{\mathrm{m}}^{2}}{2 \rho\left(\mathrm{C}_{\mathrm{d}} \mathrm{A}\right)^{2}}
$$

Where $\dot{\mathrm{m}}$ is the propellant mass flow, $\mathrm{kg} / \mathrm{s}$ and $\mathrm{A}$ is the opening area of injector, $\mathrm{m}^{2}$. The discharge coefficient for office $\mathrm{C}_{\mathrm{d}}=0.9$ is chosen according to orifice shape [3]. The designer usually tends to maintain injector and support plates with a minimum pressure drop. The calculated pressure drop for each plate is $\approx 0.01 \mathrm{bar}$.

- Catalytic bed loss:

The pressure drop $\Delta \mathrm{P}_{\mathrm{b}}$ across packed bed namely evaluated using empirical equation as [9].

$$
\begin{aligned}
& \Delta P_{b}=\frac{C_{1} G_{b}^{1.95}}{P_{c}^{0.9}}+C_{2} t \\
& =0.35 \text { bnar }
\end{aligned}
$$

Where: $\quad=.35$ bar

$\mathrm{G}_{\mathrm{b}} \quad$ Throughput, $\mathrm{lb} / \mathrm{in}^{2} \mathrm{~s}$

$\mathrm{P}_{\mathrm{c}} \quad$ Chamber pressure at the end of the catalytic bed, psi

$\mathrm{t} \quad$ Accumulated running time, $\mathrm{s}$

$\mathrm{C}_{1}, \mathrm{C}_{2} \quad$ Constants determined experimentally for a given bed design, $\mathrm{C}_{1}=0.504$, $\mathrm{C}_{2}=14.7 \mathrm{psi} / \mathrm{s}$

- Nozzle part loss

The theoretical correction factor $\lambda$ can be applied with a conical nozzle as,

$$
\lambda=1 / 2(1+\cos \alpha)
$$

The nozzle divergent angle is taken as $15^{\circ}$, the calculated correction factor $\lambda=0.983$

\section{THE FINAL THRUSTER DESIGN}

The major design parameters are $\mathrm{H}_{2} \mathrm{O}_{2} 85 \%$ concentration, decomposition efficiency $\approx 87 \%$, operating pressure $=10 \mathrm{bar}$, theoretical characteristic velocity $=884.5 \mathrm{~m} / \mathrm{s}$, specific impulse $=$ $1114.9 \mathrm{~m} / \mathrm{s}$, specific heat ratio $=1.318$, all these data are chosen or investigated by NASA's CEA code [4] with certain assumptions, include steady-state frozen flow, ideal gases; all exhaust products in the gas phase, neglecting boundary and friction effects, gases leaving the nozzle exit in the axial direction and chemical equilibrium, as shown in Table (5).

Table (5) Thermo-chemical results for design $\mathrm{H}_{2} \mathrm{O}_{2}$ concentrations

\begin{tabular}{|c|c|c|c|c|c|c|c|c|}
\hline $\mathrm{H}_{2} \mathrm{O}_{2} \%$ & $\begin{array}{c}\text { Mole fraction } \\
\mathrm{H}_{2} \mathrm{O} \text { steam }\end{array}$ & $\begin{array}{c}\text { Mole fraction } \\
\mathrm{O}_{2} \mathrm{gas}\end{array}$ & $T_{c}, \mathrm{~K}$ & $\begin{array}{l}I_{s p}, m \\
/ s\end{array}$ & $A_{e} / A_{t}$ & $\gamma$ & $C^{*}, \mathrm{~m} / \mathrm{s}$ & $\rho, \mathrm{kg} / \mathrm{m}^{3}$ \\
\hline 85 & 0.7273 & 0.2728 & 907.3 & 1114.9 & 2.0663 & 1.318 & 884.5 & 0.4902 \\
\hline 90 & 0.7076 & 0.2924 & 1029.6 & 1183.1 & 2.0826 & 1.309 & 940.1 & 0.4313 \\
\hline
\end{tabular}

The design process started with design requirement as follows:

1) A $5 \mathrm{~N}$ average thrust, 
2) Simplicity, availability and safety,

3) Pulsed and steady state operations.

The NASA CEC71 software [4] was utilized to investigate and analyse the thruster performance parameter. Figure (7) Shows the sequence of the conceptual design which was performed during this study. The design specifications will be assessed and refined during the experimental work.

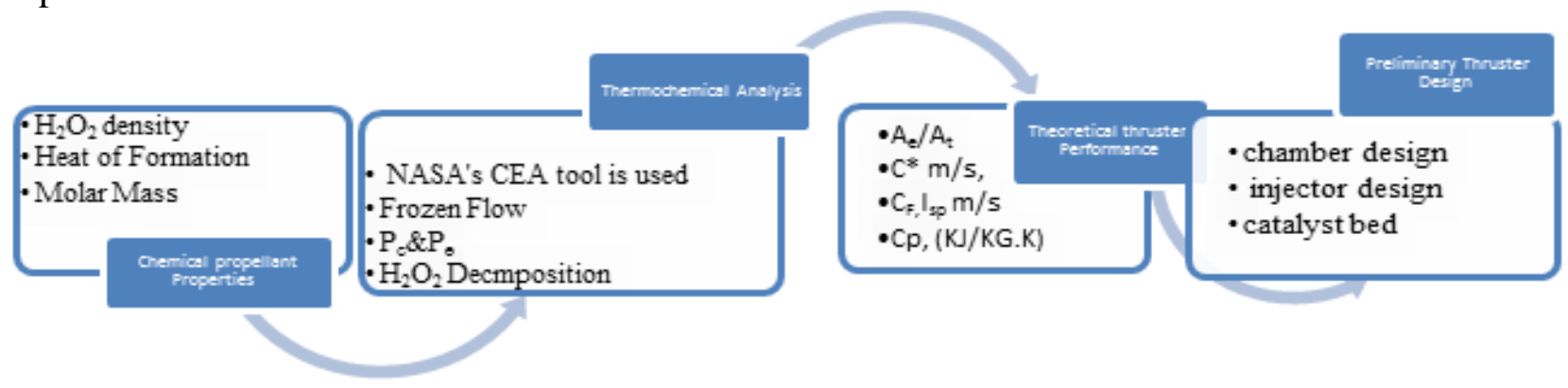

Fig. (7) The sequence of the conceptual design

The final results from thermochemical calculation are:

- Operating pressure $P_{c}=10$ bar,

- Characteristic velocity $C_{t h}^{*}=884.5 \mathrm{~m} / \mathrm{s}$,

- Specific impulse $I_{s p}=1114.9 \mathrm{~m} / \mathrm{s}$,

- Specific heat ratio $\gamma=1.318$,

- $\quad$ Chamber temperature $T_{c}=907.3 \mathrm{~K}$.

The theoretical characteristic velocity based on the following relation [3]:

$$
C_{t h}^{*}=\sqrt{\frac{R T_{c}}{\gamma}}\left(\frac{\gamma+1}{2}\right)^{\frac{1+\gamma}{2(\gamma-1)}}
$$

The decomposition efficiency $\approx 0.87$ is basically dependent on the catalyst bed quality, the actual characteristic velocity $C_{a c t}^{*}$ is $=0.87 C_{T h}^{*}$

The loading factor (LF) is taken as $50 \mathrm{~kg} / \mathrm{s} \mathrm{m}^{2}$. So the area of the injector is

$$
\mathrm{A}_{\text {inj }}=\dot{\mathrm{m}} / \mathrm{LF}
$$

Assuming the orifice diameter $=2 \mathrm{~mm}$, the number of holes is $=23$ holes to satisfy opening area $\approx 50 \%$

The nozzle part parameters are designed based on the following equations.

Area ratio

$$
\frac{A_{e}}{A_{t}}=\frac{1}{M_{e}}\left[\frac{2}{\gamma+1}\left(1+\frac{\gamma-1}{2} M_{e}{ }^{2}\right)\right]^{\gamma+1 / 2(\gamma-1)}
$$

Thrust coefficient $C_{F}=\gamma \sqrt{\left(\frac{2}{\gamma+1}\right)^{\frac{\gamma+1}{\gamma-1}}} \sqrt{\frac{2}{\gamma-1}\left[1-\left(\frac{P_{e}}{P_{c}}\right)^{\gamma-1 / \gamma}\right]}+\left(\frac{P_{e-} P_{a}}{P_{c}}\right) \frac{A_{e}}{A_{t}}$

Nozzle critical diameter

$$
\begin{gathered}
A_{t}=\frac{F}{C_{F} P_{C}} \\
m^{\prime}=\frac{P_{c} A_{t}}{C_{a c t}^{*}}
\end{gathered}
$$

Mass flow rate

$$
L_{\text {con }}=\frac{R_{e-} R_{t}}{\tan \theta}
$$

Eq.

The nozzle divergent length

Table (6) summaries the conceptual design parameters of MPT. Figure (8) illustrates the MPT layout and dimensions 
Table (6) Conceptual design for mono-propellant thruster

\begin{tabular}{|c|c|c|}
\hline & Parameter & Value \\
\hline \multirow[t]{2}{*}{ Propellant } & $\mathrm{H}_{2} \mathrm{O}_{2} 85 \%$ & \\
\hline & Mass flow rate, $\mathrm{g} / \mathrm{s}$ & 5.0 \\
\hline \multirow[t]{5}{*}{ Catalytic bed } & Sliver mesh material & \\
\hline & inner diameter, $\mathrm{mm}$ & 14.6 \\
\hline & Length/diameter ratio & 4.0 \\
\hline & Loading factor, $\mathrm{kg} / \mathrm{s} \mathrm{m}^{2}$ & 50.0 \\
\hline & Total number of packed screens & 78 \\
\hline \multirow[t]{4}{*}{ Nozzle part } & Conical nozzle shape & \\
\hline & Throat diameter, $\mathrm{mm}$ & 2.25 \\
\hline & Exit diameter, mm & 3.32 \\
\hline & Nozzle half angle, deg & 15.0 \\
\hline \multirow[t]{6}{*}{ Injection plate } & Drill injector shape & \\
\hline & Opening area, $\%$ & 50 \\
\hline & Diameter, $\mathrm{mm}$ & 14.6 \\
\hline & Orifice diameter, $\mathrm{mm}$ & 2.0 \\
\hline & Number of orifices & 23 \\
\hline & Thickness, mm & 2.0 \\
\hline \multirow[t]{6}{*}{ retainer } & Square shaped mesh & \\
\hline & Opening area, \% & 50 \\
\hline & Diameter, mm & 14.6 \\
\hline & Square opening, $\mathrm{mm}$ & $2.0 \times 2.0$ \\
\hline & Number of square openings, & 25 \\
\hline & Thickness, mm & 2.0 \\
\hline \multirow{6}{*}{$\begin{array}{l}\text { Thruster } \\
\text { performance }\end{array}$} & Thrust range, $\mathrm{N}$ & 5 \\
\hline & Specific impulse, $\mathrm{s}$ & 1114.9 \\
\hline & Characteristic velocity, $\mathrm{m} / \mathrm{s}$ & 884.5 \\
\hline & Chamber temperature, $\mathrm{K}$ & 907.3 \\
\hline & Thrust coefficient & 1.256 \\
\hline & mass flow rate, $\mathrm{g} / \mathrm{s}$ & 4.87 \\
\hline
\end{tabular}




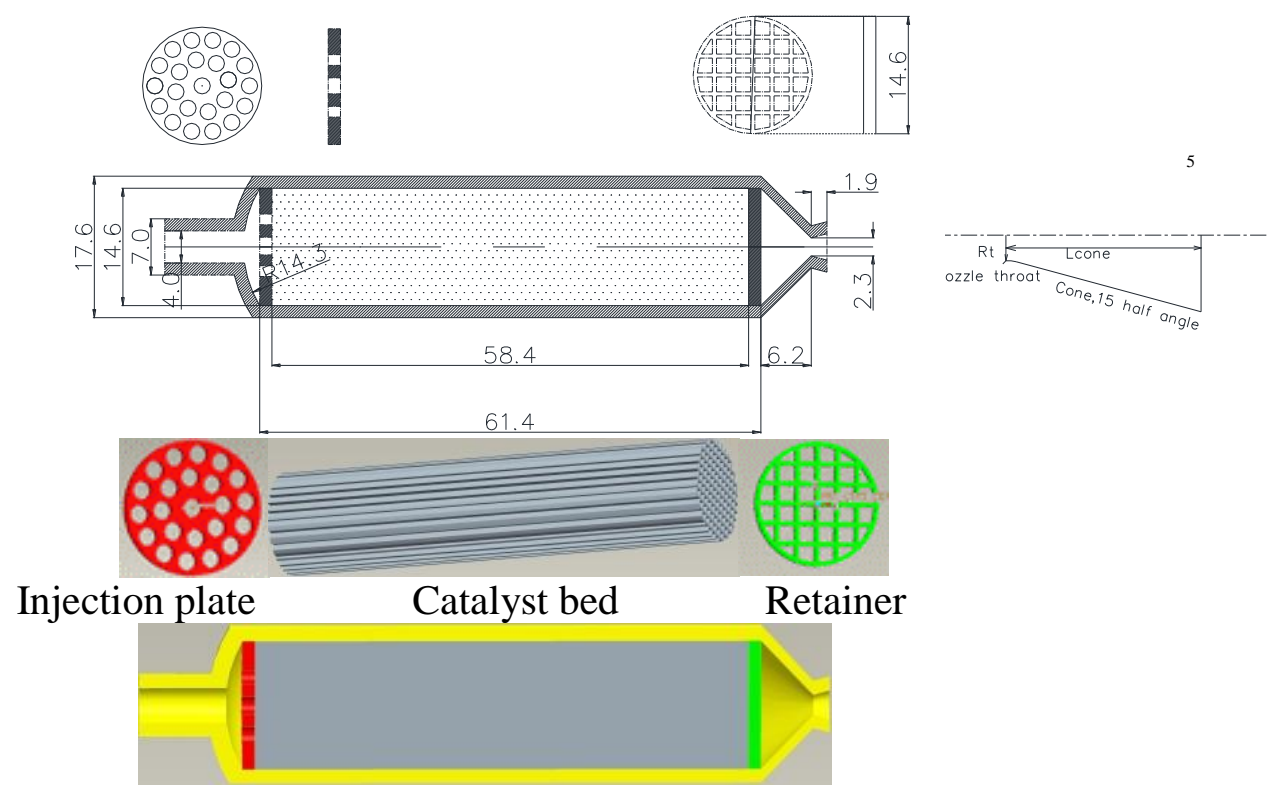

\section{CONCLUSION}

Fig. (8) MPT design scheme

$\mathrm{H}_{2} \mathrm{O}_{2}$ MPT is designed for operation in both steady state and pulse mode over a wide pressure range .It's ideal for propulsion systems operating in blow-down mode. This thruster offers an inexpensive, high performance option for LEO remote sensing satellite.

This renewed interest in $\mathrm{H}_{2} \mathrm{O}_{2}$ is due to significant cost saving, efficient storability (3-5 years) and simple safety procedure so it is considered as a green propellant. Moreover, utilization of $\mathrm{H}_{2} \mathrm{O}_{2}$ in propulsion provide the capability of operating the propulsion system on dual mode as bipropellant for a large thrust applications and a monopropellant mode for a small thrust requirement .

The results of a theoretical performance analysis are carried out using NASA's CEA tool with changing concentration of $\mathrm{H}_{2} \mathrm{O}_{2}, \mathrm{P}_{\mathrm{C}}$ and $\mathrm{H}_{2} \mathrm{O}_{2} \mathrm{~T}_{i}$ show that:

- As the concentration of $\mathrm{H}_{2} \mathrm{O}_{2}$ increases, $T_{C}$ and $I_{s p}$ increase proportionally at the same $P_{C}$.

- As the concentration of $\mathrm{H}_{2} \mathrm{O}_{2}$ increases, the amount of the decomposed $\mathrm{O}_{2}$ increases proportionally. The amount of the decomposed $\mathrm{O}_{2}$ at $\mathrm{H}_{2} \mathrm{O}_{2}$ concentration of $95 \%$ is $50 \%$ higher than $\mathrm{H}_{2} \mathrm{O}_{2}$ concentration of $70 \%$.

- It is also noticed that increasing $P_{C}$ from 7 bar to 10 bar increases the $I_{s p}$ more than increasing $P_{C}$ from 10 bar to 13 bar and from 13 bar to 16 bar. Therefore, the value of the $P_{C}$ should be optimized because increasing the value of $P_{C}$ won't contribute significantly in improving the thruster performance; on the other hand, it puts restriction on the thruster material selection to choose a material can withstand the high pressure which may complicate machining process of the thruster and increase the thruster mass too. Moreover, increasing the pressure of the feeding system.

- Increasing $\mathrm{H}_{2} \mathrm{O}_{2} \quad T_{i}$ increases $I_{s p}$ and $\mathrm{C}^{*}$ at the same value of $P_{c}$ for different $\mathrm{H}_{2} \mathrm{O}_{2}$ concentrations so it enhances the performance of the thruster. It is also noticed that the contribution of increase of $\mathrm{I}_{\mathrm{sp}}$ and $\mathrm{C}^{*}$ by increasing the $\mathrm{H}_{2} \mathrm{O}_{2} T_{i}$ decreases slightly by increasing the $\mathrm{H}_{2} \mathrm{O}_{2}$ concentrations. Practically, increasing $\mathrm{H}_{2} \mathrm{O}_{2} T_{i}$ consumes more power which increases the power budget of the satellite which is not recommended.

All the findings concerning the effect of changing the $\mathrm{H}_{2} \mathrm{O}_{2}$ concentration, decomposition chamber pressure, and $\mathrm{H}_{2} \mathrm{O}_{2}$ temperature on the thruster performance are taken into consideration during the manufacturing and firing tests of MPT. 


\section{REFERENCES}

1. Lucio Torre ,Antony J. Musker, Antony J. Musker, Graham T "Development of Hydrogen Peroxide Monopropellant" 42 ${ }^{\text {nd }}$ AIAA, Joint Propulsion Conference, USA, 2006.

2. R., Robles. "Thermochemical Calculation Anaylysis of Hydorgen Peroxide with Application to Rocket Design" San Jose Staate University, USA, 2002.

3. Sattun, George "Propulsion Sytems Elements” ISBN 0-471-32642-9, New York, 2000.

4. NASA "Computer Program for Calculation of Chemical Equilibruim Composition and Application”.

5. Davis,N\&Mccormick,J. Newyork "Design of Catalyst Packs for the Decompostion of Hydrogen Peroxide” Progress in Astornautics \&Rocketry, 1660, Vol. 2.

6. Norazila Othman, Subramaniam Krishnan and Mohammad Nazri Mohd Jaafar "DESIGN AND TESTING OF A 50N HYDROGEN PEROXIDE”, ., Vol. No 33, P 70-81. 2011

7. Matthew J. Palmer1, Graham T. Roberts2, Antony J. Musker "Design, Build and Test of a 20N Hydrogen Peroxide Monopropellant Thruster"., 47th AIAA,. San Diego, California,USA, 2011

8. A. Pasini1, L. Torre2, L. Romeo3, Angelo Cervone4 and L. d'Agostino5"Endurance Tests on Different Catalytic Beds for H2O2 Monopropellant Thrusters" $45^{\text {th }}$

AIAA/ASME/SAE/ASEE Joint Propulsion Conference \& Exhibit 2-5 August 2009, Denver, Colorado

9. Dieter K. Huzel and David H. Huang "Modern engineering or design of liquid-propellant liquid engines" ISBN 1-56347-013-6,Washington DC, 1992 